\title{
Learning to See Words
}

\author{
Brian A. Wandell ${ }^{1}$, Andreas M. Rauschecker ${ }^{1,2}$, and Jason D. Yeatman ${ }^{1}$ \\ ${ }_{1}^{1}$ Psychology Department, Stanford University, Stanford, California 94305 \\ ${ }^{2}$ Medical Scientist Training Program and Neurosciences Program, Stanford University, Stanford, \\ California 94305
}

\begin{abstract}
Skilled reading requires recognizing written words rapidly; functional neuroimaging research has clarified how the written word initiates a series of responses in visual cortex. These responses are communicated to circuits in ventral occipitotemporal (VOT) cortex that learn to identify words rapidly. Structural neuroimaging has further clarified aspects of the white matter pathways that communicate reading signals between VOT and language systems. We review this circuitry, its development, and its deficiencies in poor readers. This review emphasizes data that measure the cortical responses and white matter pathways in individual subjects rather than group differences. Such methods have the potential to clarify why a child has difficulty learning to read and to offer guidance about the interventions that may be useful for that child.
\end{abstract}

\section{Keywords}

reading; visual word form area; dyslexia; visual field maps; diffusion tensor imaging (DTI); fMRI

\section{INTRODUCTION}

Although most children learn to read well, there are many who fail to learn or learn only with great difficulty. There are many reasons why a child may have difficulty learning to read. These reasons range from social impediments that limit training to biological impediments within specific brain structures. The research we review here is aimed at clarifying the neural circuits essential for reading and at understanding specific failure modes that may arise in the brain systems of a child learning to read in a supportive environment.

Many modern neuroimaging methods can trace signals and structures of specific neural pathways in a single subject. Using these methods, the signals and structures in a child who is having difficulty reading can be compared to the corresponding measurements obtained from a cohort of good readers. This analysis is not a group comparison (poor readers versus good readers). Rather, it is an engineering approach to understanding disability in individuals. We begin with the assumption that all good readers operate within a compliance range ["Happy families are all alike; every unhappy family is unhappy in its own way"

\footnotetext{
(C) 2012 by Annual Reviews. All rights reserved

Correspondence to: Brian A. Wandell; Andreas M. Rauschecker; Jason D. Yeatman.

wandell@stanford.edu, andreasr@stanford.edu, jdyeatman@stanford.edu.

DISCLOSURE STATEMENT

The authors are unaware of any affiliation, funding, or financial holdings that might be perceived as affecting the objectivity of this review.
} 
(Tolstoy 1911)]. We aim to find the specific signals and structures that are outside of this compliance range in an individual who has difficulty reading. Problems may arise for many reasons. Some may be due to developmental failures of the systems dedicated to reading per se, whereas others may be due to inadequate signals from related but essential systems, such as the visual or auditory systems. With enough experience we may hope to learn which neural systems commonly limit reading and ultimately to understand the underlying genetic or environmental biological factors that cause these deviations.

Given that widespread literacy is a relatively recent development, it is likely that many components of the reading circuitry are used for purposes in addition to reading. For example, to read a child must develop adequate visual acuity and learn to understand speech. Competence at these tasks is predictive of future reading: Children who are efficient at hearing and manipulating the sounds of speech are usually good at learning to read (Shaywitz et al. 2008, Torgesen et al. 1999, Wagner \& Torgesen 1987). The development of reading relies on the proper developmental progression of all of these systems. Once the preconditions for reading are met, the next step is to learn the association between orthography (i.e., the written or printed symbols) and language sounds. A child who does not learn this skill, as measured by single-word reading, will not reach an efficient level of reading. A deficit in learning single-word reading in a child of normal intelligence is called developmental dyslexia.

We can now preview our main points. First, skilled single-word reading depends on the correct processing in a series of cortical circuits. Some of these circuits are in classic visual cortex; others are in regions identified by investigators working on reading and language. It is important to consider the development of all reading circuits jointly. In preparing this review, we have learned that there is room to improve how investigators localize and coordinate these measurements. Second, reading circuitry includes local cortical circuits and their connecting white matter tracts; this hierarchy of processing stages must develop in a temporal sequence. Certain brain systems must develop and provide signals to other systems, or else the entire circuit specialization for reading will not develop properly. Understanding the system should include measuring the sequence of development in individual subjects.

To take a practical approach to understanding reading failures, we need to know both the parts list and the sequence-of-assembly instructions for the reading circuitry. There has been good progress on all fronts, and there remains much to be done.

\section{BACKGROUND}

The past 30 years have transformed our ability to measure signals and structures in the human brain. The earliest human neuroimaging measurements included experiments to understand reading and language. The rich neurological history of reading and language formed an excellent basis for these early investigations (Binder et al. 1992; Damasio \& Damasio 1983; Dejerine 1891, 1895; Wernicke 1906). The earliest experiments used positron emission tomography (PET); subsequent advances in magnetic resonance imaging (MRI), magnetoencephalography (MEG), and electroencephalography (EEG) built on this history and provided a great deal of new and more precise information about neural signals and structures (Wandell 2011).

An important part of that history was an effort to classify neural structures into sensory (visual) and language. Indeed, the nineteenth-century neurological literature opens with a dispute between Dejerine and Wernicke as to whether the neural basis of reading was intimately connected with visual cortex or alternatively whether reading is embedded within a language system and relies only on generic visual information (Bub et al. 1993). This 
debate continues in the modern era (McCandliss et al. 2003, Price \& Devlin 2003, Wandell 2011). As we have learned more about the visual system using modern neuroimaging, it appears that the focus on this question is not helpful in several ways. For example, modern imaging methods show that even activity in primary sensory areas of the brain, such as the lateral geniculate nucleus (LGN) and primary visual cortex (V1), are modulated by taskdependent manipulations such as shifts in attention (Brefczynski \& DeYoe 1999, Gandhi et al. 1999, O'Craven et al. 1997). Moreover, allowing for separations of only two or three synapses, anatomical studies show that cortex is massively interconnected (Braitenberg \& Schüz 1991). An alternative approach is to study how reading signals are communicated in the brain and the operational compliance range for these signals and structures. We point out three advances here, and we spend most of this review describing the experimental basis of these advances.

\section{Critical Neural Circuitry for Seeing Words Is Located in Ventral Occipitotemporal Cortex}

Since the French neurologist Dejerine described a patient with pure alexia (word blindness) caused by brain damage (Dejerine 1892), the idea of a neural structure critical for seeing words has been influential in theories of reading (Bub et al. 1993). Many such patients have since been described, and neurological lesions tend to overlap in ventral occipitotemporal (VOT) cortex and the splenium of the corpus callosum (Damasio \& Damasio 1983). In the 1990s, modern imaging methods allowed investigators to search for the likely position of cortical circuits essential for reading in healthy subjects. Measurements using MEG, PET, and MRI of neurological lesions, and intracranial recordings initially emphasized somewhat different parts of cortex (Allison et al. 1994; Howard et al. 1992; Nobre et al. 1994; Paulesu et al. 1995; Petersen et al. 1988; Petersen \& Fiez 1993; Price et al. 1994, 1998; Salmelin et al. 1996; Wandell 2011). By the year 2000, however, Cohen and colleagues summarized the findings by asserting the existence of "a standard model of word reading" that includes "a left inferior temporal region that is specifically devoted to the processing of letter strings" (Cohen et al. 2000). In a confident and controversial move, Cohen and Dehaene labeled the particular VOT region they studied as the visual word form area (VWFA), which added cortical specificity to the classic notion that there is a visual word form system (Warrington $\&$ Shallice 1980). This term has endured ${ }^{1}$ despite the reluctance of some authors to make such a specific and strong functional assignment (Price \& Devlin 2003, 2004). At present, there is consensus that a role for VOT signals in reading does not deny a significant role for other VOT circuit functions or that nonvisual factors influence responses in VOT cortex (Xue et al. 2006, Yoncheva et al. 2010).

Over this same period, a great deal also has been learned about the organization of human visual cortex (Wandell et al. 2007, Wandell \& Winawer 2010). We learned that responses to many types of visual stimuli extend into VOT cortex, and regions within VOT are particularly responsive to specific types of visual signals, including color and specific classes of images (Epstein \& Kanwisher 1998, Kanwisher 2001, Kanwisher et al. 1997, Zeki 2005, Zeki et al. 1991). These circuits develop over time (Rossion et al. 2002, Tarr \& Gauthier 2000), and during the years when we teach children to read, the VOT circuits change their responses (Ben-Shachar et al. 2011, Booth et al. 2001, Brem et al. 2010, Maurer et al. 2010).

\footnotetext{
${ }^{1}$ A PubM Developmental dyslexia d search of the period 2000 to 2011 identified more than 150 published papers that included the phrase "visual word form area."
} 
Critical White Matter Pathways for Reading Can Be Identified Using Diffusion Imaging, and the Tissue Properties of These Pathways Correlate with Reading Performance

As recently as 15 years ago, there were no noninvasive methods for identifying the major white matter fiber tracts in the living human brain and measuring the tract properties. The development of diffusion imaging methods has changed this situation entirely, so that measurements of the large axon bundles carrying information between cortical regions are now straightforward and performed widely (Conturo et al. 1999, Mori 2007, Mori et al. 1999). Properties of such tracts can be compared across groups (e.g., good versus poor readers), monitored over time (e.g., as children learn to read), and measured in individual subjects (e.g., dyslexic individuals). Although current technology reliably identifies the large fiber tracts located near the middle of the brain, it is not yet possible to confidently identify tracts located at the edges of the white matter, such as where the tracts enter the gray matter folds.

There has been good progress in identifying which large tracts carry signals important for reading (Ben-Shachar et al. 2007c). Many of these studies further identify correlations between the tissue properties of these tracts and specific aspects of skilled reading (Beaulieu et al. 2005, Deutsch et al. 2005, Klingberg et al. 2000, Niogi \& McCandliss 2006). The reliably identified fiber tracts are mainly located in regions that carry signals between auditory and language regions, or perhaps between visual and language cortex. The tissue properties of the fiber tracts, for example their degree of myelination, develop significantly through the first 20 years of life (Bourgeois \& Rakic 1993, Lebel et al. 2008, Sowell et al. 2004). The current measurements reveal significant correlations between reading or readingrelated behaviors and tissue properties in these tracts. So far, the most consistently observed correlations between white matter tract tissue properties and reading performance are related to the phonological aspects of reading performance, but this field is nascent and further discoveries will follow.

\section{Structures and Signals in Reading Circuits Change During Development and Are Influenced by Training}

Both cross-sectional and longitudinal studies have measured the typical development of signals and structures in the reading circuitry (Ben-Shachar et al. 2011, Booth et al. 2001, Brem et al. 2010, Helenius et al. 1999, Maurer et al. 2010, Turkeltaub et al. 2008). There is good agreement across methods and studies that VOT responses and specific white matter structures change with development and that there are correlations between these changes and reading performance. Investigators have also tested whether specific reading interventions change group responses in locations that are part of the neural circuitry of reading (Shaywitz et al. 2004, Simos et al. 2002, Temple et al. 2003).

In summary, instrument sensitivity and signal-processing methods have advanced enormously over the past 30 years. We can assess functional signals and white matter tracts in single subjects during the ages they are learning to read. Data from individuals can be compared with corresponding signals and structures in other subjects from the same age cohort, and in this way neuroimaging tools can help to identify the neural basis for reading difficulties in a particular child. As we accumulate more data, it should be possible to classify individuals according to particular individual differences. We may then be able to devise behavioral tests and individualized training paradigms to identify specific deficits and improve corresponding systems.

\section{FUNCTIONAL NEUROIMAGING OF VISION AND READING}

In addition to advances in neuroimaging instrumentation, the past 30 years has seen great progress in the associated signal-processing and visualization methods. The processing and 
visualization of the measurements is particularly helpful in coordinating findings from different laboratories or subdisciplines. In this section, we offer an overview of the spatial organization in the posterior regions of the brain, from the occipital pole to VOT. The goal of this overview is to summarize the findings and to explain limitations in current measurements. Our understanding of the spatial layout of these responses is mainly obtained using functional magnetic resonance imaging (fMRI). Our knowledge about the stimulus specificity and response development comes from a range of different techniques.

\section{Visual Field Maps}

A century ago, neurologists discovered that human posterior cortex contains at least one map of the retina: nearby neurons respond principally to stimuli in nearby retinal locations (Henschen 1893, Holmes et al. 1996, Inouye 1909). Over the next 50 years, multiple maps were discovered in a variety of animal species (Van Essen et al. 2001, Wandell et al. 2007), but as recently as 25 years ago, the number and spatial organization of the human maps were uncertain (Horton \& Hoyt 1991a,b). During the past 25 years, we learned that visual field maps tile virtually all of occipital cortex and that maps are also present in parietal and temporal cortex (Wandell \& Winawer 2010).

The general organization of the human retinotopic maps is the same in different individuals (Figure 1, see color insert), although the absolute size of the maps varies by severalfold (Andrews et al. 1997, Dougherty et al. 2003, Stensaas et al. 1974). V1 is located in the calcarine sulcus. V1 receives input from the retina via the LGN, and it also receives substantial feedback connections from other parts of cortex. Neurons in V1 respond to visual stimuli in the contralateral hemifield.

In primates, $\mathrm{V} 1$ is surrounded by two additional maps, $\mathrm{V} 2$ and $\mathrm{V} 3$, that also respond to stimuli in the contralateral visual field. A series of maps extend anterior from V2/V3 on both the dorsal and ventral surfaces. Together, these maps cover the occipital lobe and much of the posterior temporal and parietal lobes. A strip within the VOT has not been identified as retinotopic. This region is surrounded by retinotopic cortex laterally (LO-1, LO-1, TO-1, and TO-2) and medially (hV4, V0-1, VO-2, PHC-1, and PHC-2). As techniques for measuring maps improve, new maps continue to be reported. Regions on the lateral surface of occipital and temporal cortex that were thought to be nonretinotopic (Tootell et al. 1996) have now been mapped; visually responsive regions not yet identified as retinotopic may be revealed as retinotopic as measurements improve.

Currently, two significant methodological problems limit fMRI measurements in VOT. First, the anterior portion of the VOT is on the ventral portion of the temporal lobe, near the auditory canal. There is a significant difference in magnetic susceptibility between the brain and the auditory canal. Special methods are needed to obtain reliable fMRI signals in regions near large susceptibility changes, and these methods are not performed in most fMRI experiments. Second, a large vein - the transverse dural sinus-passes near the surface of VOT. This vein often passes near the hV4 map and travels forward toward the anterior temporal lobe over the nonretinotopic region of VOT. The magnetic field near this vein is inhomogeneous, and this interferes with fMRI measurements (Winawer et al. 2010). The artifact from this venous sinus is quite large when measuring with 3-mm voxels, and somewhat smaller for $1.5-\mathrm{mm}$ voxels ( $\mathrm{K}$. Weiner, personal communication). The precise relationship of the artifacts, caused by anatomical structures, in relation to functional tissue such as the visual field maps can vary across individuals. However, neither of these artifacts - the auditory canal susceptibility or the transverse dural sinus-is removed by averaging. It is possible that new methods will develop that enable reliable measurements of the responses in these VOT regions. For now, the reader should understand that even though 
important signals can be identified, investigators do not have a clear view of responses in the entire VOT cortex.

\section{Early Visual Cortex}

A written word stimulus evokes a response pattern in the cone photoreceptors and retinal neurons. These signals are communicated to the LGN and ultimately to V1 and other cortical maps for further processing. The cortical activity evoked by printed words in successive stages of the visual hierarchy (V1, V2, V3, and hV4) can be measured in individual subjects (Figure 2, see color insert). The response to a small word is confined to discrete locations within each of the visual field maps at a position determined by the location of the word form in the visual field.

These measurements confirm that the signal is passing through visual cortex, and the amplitude and spatial distribution of the activity can be tested against the expected distribution. But important diagnostic information is missing from these blood oxygen-level dependent (BOLD) measurements. The circuitry communicates in both directions between most of the connections: say, from the LGN to V1 and then from V1 back to the LGN, or from V1 to V2 and vice versa. The timing of the BOLD signal used in most fMRI applications is too slow to separate these interacting signals. It is entirely possible that one side of this signaling system is deficient, but not the other. In theory, a deficit in either the feedforward or feedback signal could lead to an unexpected fMRI signal in, say, primary visual cortex (Wandell \& Smirnakis 2009). To distinguish these signals requires the use of technologies with better temporal resolution. Significant advances have been made in the methods for coordinating EEG measures with structural MRI measures and for localizing these signals to cortical structures (Appelbaum et al. 2006, Dale \& Sereno 1993, Hagler et al. 2009).

\section{Motion-Selective Cortex}

There is a series of retinotopic maps on the lateral surface at the occipital-temporal border (Amano et al. 2009, Huk et al. 2002, Kolster et al. 2010) (Figure 2). Several of these maps appear to be homologous to visual area middle temporal (MT) and its surrounding maps in animal models. The maps in this region are called the human motion complex, or hMT+. In animal models, MT was identified first by its retinotopic map; subsequently, it was found to have a large population of motion-direction-selective neurons (Zeki 1980, 2005) and dense myelination. The homologous region was identified in human because of its strong response to moving stimuli (Tootell et al. 1995, Zeki et al. 1991) and comparable myelination (Tootell \& Taylor 1995).

One prominent theory of reading disability is that magnocellular neurons in the LGN, which are the main source of stimulus-driven excitation for MT (Maunsell et al. 1990), are dysfunctional in poor readers (Cornelissen et al. 1998; Livingstone et al. 1991; Lovegrove et al. 1980, 1982; Stein 2001). Three groups have confirmed that hMT+ responses are weaker in poor readers compared with controls (Demb et al. 1997, Eden et al. 1996). HMT+ is responsive during reading, and there is a relationship between performance on phonological awareness tasks and contrast sensitivity of motion-selective cortex in controls (Ben-Shachar et al. 2007a). The relationship between hMT+ responses and other parts of the reading circuitry is not yet understood. But if one believes that visual cortex learns to recognize specific patterns associated with word forms, it is plausible that hMT+ regions learn the specific pattern of eye movements and control of attention that are used in skilled reading. Perhaps hMT+ circuitry learns these elements of reading behavior (Wandell 2011). 


\section{Ventral Occipitotemporal Cortex}

Several visual specializations are located within VOT cortex (Figure 1), a region nestled between the ventral occipital maps (VO-1, VO-2) and the hMT+ maps (TO-1, TO-2). Both the VWFA) and a face-selective region (the fusiform face area, FFA) are located within VOT. These regions are in close proximity to one another and both are near the foveal representation of the VO retinotopic visual field maps. It is not common for investigators to measure both visual field maps and these object-selective responses; consequently, we have much less information than we should about the spatial arrangement of these regions.

Several VWFA response sensitivity properties support the hypothesis that the VWFA is a reading specialization. These are: $(a)$ VWFA responses are insensitive to retinotopic position (Cohen et al. 2002) and leTTeR CaSe (Dehaene et al. 2001, 2004), (b) lesions near the VWFA can produce pure alexia (Cohen et al. 2003, Gaillard et al. 2006, Leff et al. 2001, Warrington \& Shallice 1980), (c) VOT responses are sensitive to bigram frequency (Binder et al. 2006, Vinckier et al. 2007), (d) there is a word-specific pattern of orthographic priming in VWFA (Dehaene et al. 2001), and (e) VWFA responses differ between words and their mirror images (Dehaene et al. 2010a, Pegado et al. 2010). But the data supporting these claims are not complete. For example, the assertion of position invariance or case insensitivity is supported by coarse measurements, but this observation may be overturned as measurement resolution and sensitivity increase.

There are two general hypotheses as to why the VWFA responds more powerfully than other cortical locations while subjects view words (Ben-Shachar et al. 2007c). One hypothesis is that the VWFA circuits learn to respond to the specific line contours in word forms (Szwed et al. 2009). The relatively large responses to words, then, are present because VOT circuits become specialized from exposure to hundreds of thousands of words. A second hypothesis is that the VWFA is simply the location in visual cortex that is most densely interconnected with language regions (Devlin et al. 2006, Powell et al. 2006, Twomey et al. 2011). On this view, word-specific responses arise because there is an interaction between language systems and visual cortex during reading. This hypothesis is supported by the evoked potential data showing that lateralization of the putative VWFA response appears to follow the lateralization of language (Cai et al. 2008) and that auditory signals can modulate the response of VOT (Dehaene et al. 2010b, Yoncheva et al. 2010). These two hypotheses are not mutually exclusive and may both turn out to be true.

Analyses of the VWFA are advancing, and two issues should be resolved in the next few years. First, the spatial relationship between the retinotopic maps and the VWFA and FFA regions should clarify. Until quite recently, very few groups measured visual field maps, the VWFA, the FFA, and other specializations simultaneously (Ben-Shachar et al. 2007b, Brewer et al. 2005, Szwed et al. 2011). Understanding the spatial relationship of these regions requires measurements in individual subjects at relatively high spatial resolution. For example, one recent high-resolution $(1.4 \mathrm{~mm})$ method separates the FFA and VWFA peaks by only $9 \mathrm{~mm}$ (Song et al. 2010). Given this small separation, understanding the pattern of activity requires single-subject analyses and voxel resolutions below the typical 3 $\mathrm{mm}$.

Second, we should learn more about VWFA stimulus selectivity. Many regions of cortex respond to written text (Figure 2), and the VWFA responds to many stimulus classes. One would like a model that predicts the VWFA response to any arbitrary stimulus. Modeling these responses has not been a focus of neuroimaging. Rather, studies typically rely on the subtraction methodology and response comparisons (contrasts) between stimuli of interest (e.g., text) with a series of control stimuli. It is clear that the size of the text versus control mismatch will depend on the precise nature of the text stimulus and comparison (Szwed et 
al. 2011). Rather than contrast the response to a few types of patterns, it is preferable to build a model of the responses. This approach is being developed in visual cortex (Dumoulin \& Wandell 2008, Kay et al. 2008, Thirion et al. 2006), and it is desirable to extend these models to VOT regions-including both the VWFA and FFA. This will be a challenging task because the VWFA response can be influenced by many experimental conditions, including language tasks.

There has been some quantification of VWFA sensitivity to different stimulus classes. For example, Ben-Shachar et al. (2007b) measured the size of the VWFA sensitivity to words, false fonts, and line drawings. Because the BOLD response has no units and it is not closely tied to a specific neural signal, Ben-Shachar and colleagues used a stimulus-referred approach to quantify sensitivity (Salmelin et al. 1996, 2000; Sperling et al. 2005). Specifically, they introduced noise into these stimuli and measured the noise power when the VWFA responses were equated. The VWFA is about $15 \%$ more sensitive to words than line drawings (0.82-0.72/0.82); the VWFA is $60 \%$ more sensitive to words than false fonts $(0.82-0.3 / 0.82)$. The VWFA responds to these patterns during a variety of tasks including passive fixation even though the subject is not reading actively or involved in a language task. Sensitivity to words in the presence of noise has also been measured behaviorally; good readers are more resistant to noise than are poor readers (Sperling et al. 2005, 2006).

Based on current findings, it appears likely that the VWFA is part of the typical reading pathway; hence, assessments of reading difficulties should include tests of the responses in the VOT generally and the VWFA specifically.

\section{Development and the VOT}

Typically, children start formal reading training at age 5-6 years, toward the end of the critical period for early visual cortex (Murphy et al. 2005). One hypothesis is that instructional training should be coordinated with the process of neural development. On this view, a child's instruction should be delivered when the systems needed to learn the material are adequately developed but still have a potential for further plasticity that enables them to respond to instruction. In this case, the critical period for linking language and sensory systems should extend beyond the critical period of early visual cortex.

Decoding the visual pattern quickly is important for skilled reading. Hence, there is value in training cortex to automatize the recognition of common word forms. In engineering practice such efficiency is obtained by using memory to store information in pre-existing look-up tables. Because there will be novel patterns that may not be stored, there must also be a fallback algorithmic mechanism to decode visual patterns into phonological representations (e.g., letter-by-letter reading). Computational algorithms are typically much slower and require more energy than look-up tables, but they guarantee a reasonable decoding in most cases. These two systems are at the heart of the dual-route theory of reading (Coltheart et al. 2001, 2010). Using this theory as a framework, one would interpret learning as the process of developing the algorithm and then developing a means to store common results in the look-up table mechanism.

The neural development of word recognition is being examined by many groups. Using cross-sectional designs, many groups find a developmental change in VOT responses to single-word reading tasks (Booth et al. 2001; Brem et al. 2006, 2010; Church et al. 2008; Maurer et al. 2007; Turkeltaub et al. 2008). A theory of VOT development is that the increased response amplitude reflects the fact that children learn the automatic mapping from orthography to phonology. In a longitudinal design, Ben-Shachar et al. (2011) measured children's (age 7-15 years) VWFA responses to words presented in different levels of noise. Sensitivity increases over this age range, and the size of the increase 
correlates with the size of improvement in sight-word efficiency (rapidly recognizing a word from a nonword). The cortical surface area of the VWFA follows an interesting and perhaps surprising pattern. The size increases until the age of 12 years and then decreases.

Reading training transforms EEG responses in posterior cortex. When adults see a word, the occipital electrodes produce a small positive response followed by a larger negative response at $170 \mathrm{~ms}$ (Bentin et al. 1999, Nobre et al. 1994). The negative response amplitude is larger for words than control stimuli (word tuning). In children prior to reading instruction, the initial positive response is larger than in adults, and the negative response is $210 \mathrm{~ms}$ later (Spironelli \& Angrilli 2009). There is no word tuning. After children learn letter-speech sound correspondences, word tuning develops. The timing remains sluggish compared to adult (Brem et al. 2010, Maurer et al. 2007).

It has been proposed that learning to recognize words colonizes neighboring cortical territory that would be devoted to processing other forms, such as faces (Cantlon et al. 2011, Dehaene et al. 2010b). This hypothesis implies that learning to recognize words stretches the learning capacity of VOT cortex.

\section{Anterior Systems for Reading and Language}

Cortical circuits specialized for seeing words must communicate with circuits specialized in phonology and language, and understanding the reading circuitry requires us to specify the connections and role of these parts. For investigators comfortable with the compact orderly representation of the visual field maps, the complex array of phonological and linguistic tasks and the characterization of the cortical responses are daunting. In visual neuroscience, investigators generally agree on the parts list (V1, V2, V3, etc.). Measurements are now typically made on a single-subject level aimed at understanding and modeling the precise computations that these regions perform.

Although neuroimaging of language has not yet mapped cortical regions with similar precision, there has been progress in identifying cortical circuitry that is critical for reading and language (Jobard et al. 2003, Shaywitz et al. 2008, Vigneau et al. 2011) (Figure 3, see color insert). In a meta-analysis aimed at understanding the neural bases for the dual-route theory of reading, Jobard et al. (2003) found a set of repeatable functional activities that cluster in several distinct regions (Figure 3). This meta-analysis offers several likely target regions for projections from VOT cortex. By knowing the parts, finding connections between the circuits for seeing words and those extracting linguistic information should now be possible.

\section{WHITE MATTER PATHWAYS AND READING}

The human brain has an enormous number of neural connections. If the axons within a single cubic millimeter of cortex are laid out end to end, they extend about 3 kilometers (Braitenberg \& Schüz 1991); this shows that even at the finest scale the cortex is massively interconnected. At a coarser scale the cortical gray matter and cerebral white matter have very similar volumes. Human cortical gray matter, which contains both neurons and local connections, has a volume of roughly $460 \mathrm{~cm}^{3}$. The cerebral white matter volume, which contains exclusively connections, is nearly as large at $380 \mathrm{~cm}^{3}$ (Walhovd et al. 2005).

During development the white matter axons are guided between cortical destinations by molecular signaling mechanisms (Goodman \& Shatz 1993). Damage to certain groups of axons (fascicles) has specific neurological consequences, and a prominent view in neurology is that many of the defining characteristics of human thought can be explained by understanding these connections (Geschwind 1965a). For example, Wernicke proposed that 
cortex is a mosaic of sensory and motor representations with functions arising from cortical interactions determined by connections (Wernicke 1874).

It was not possible to identify specific fascicles in the living human brain until recently, when diffusion-weighted imaging and computational procedures enabled such measurements (Basser 1995, Conturo et al. 1999, Le Bihan et al. 2001, Mori et al. 1999). About a dozen major fascicles that carry intrahemispheric signals can be reliably identified using diffusion-weighted imaging; in addition, the corpus callosum contains major fascicles that carry interhemispheric information (Mori 2007, Wakana et al. 2004). Many smaller fascicles (U-fibers) make short-range connections $(1-3 \mathrm{~cm})$ between nearby cortical regions. These travel parallel to the cortical surface rather than diving deep into the white matter.

There are several limitations in the ability to measure human fascicles. First, fascicles are located in close proximity to one another; at certain locations it is difficult to distinguish whether a measured voxel contains axons from just one fascicle or several. Methods are just developing that appropriately estimate the core and periphery of major fascicles (Yeatman et al. 2011). Second, axons do not necessarily travel the full length of a fascicle. Some axons enter and exit along the fascicle trajectory, so that the fascicle is akin to a highway with entrances and exits (Catani et al. 2003). Hence, the axons may differ when locations along the length of a fascicle are compared. Third, the ability to find fascicles and estimate the tissue properties of these fascicles depends on a number of factors, including curvature, thickness, proximity to the cortex, and crossing fascicles. Consequently, diffusion differences between fascicles may be caused by any of these factors.

Although there are limitations, it is also true that great progress has been made. In the past 15 years we have advanced from no measurements of white matter fascicles in the living human brain to routine measurements of many fascicles. During this time we also learned about significant relationships between the fascicle properties and reading.

\section{Intra-Hemispheric Reading Pathways}

At least five large white matter fascicles are candidates for carrying signals essential for reading (Figure 4, see color insert); improper functioning of any of these may interfere with skilled reading. The optic radiation (green) connects the lateral geniculate nucleus of the thalamus and primary visual cortex. Both the inferior longitudinal fasciculus (ILF, purple) and inferior fronto-occipital fasciculus (orange) connect with visual cortex and may carry critical feedforward and feedback information. The arcuate fasciculus (AF, dark blue) comprises axons that connect with phonological regions in the temporal lobe and language areas in prefrontal cortex. Some authors prefer to describe the arcuate as part of the superior longitudinal fasciculus (light blue), though in our view the two can be distinguished at several places.

Signals traversing the relatively short distance between V1 and VOT cortex are probably carried by U-fibers, not major fascicles. But it is likely that at some point orthographic signals in VOT are communicated to more frontal areas along a major fascicle (Catani et al. 2003). It has been suggested based on neurosurgical observations that VWFA and language regions are connected by axons that enter the ILF (Epelbaum et al. 2008). The ability to securely identify the white matter carrying orthographic signals in healthy humans will be a valuable advance.

\section{The Arcuate Fasciculus}

The AF has long been considered a candidate pathway for carrying phonological and language information (Geschwind 1965a,b). Some authors have speculated about specific functionality of AF signals. One hypothesis is that AF axons carry signals used for the 
manipulation and articulation of phonological information (Hickok \& Poeppel 2004, 2007). Another is that AF signals reactivate phono-logical material in verbal working memory (Friedmann \& Gvion 2003) and short-term storage and verbal repetition of speech (Catani \& Ffytche 2005, Glasser \& Rilling 2008, Rilling et al. 2008, Saur et al. 2008). The AF is a large bundle, and all of these hypotheses may be true (Bernal \& Ardila 2009).

Most of our knowledge about reading and the AF are based on neurological cases, and these models are based on interpreting the correspondence between lesion sites and behavioral deficits. For example, using methods to compare diffusion data from a single individual to a group of healthy controls, Rauschecker et al. (2009) report the case of a child without an arcuate who was unable to develop skilled reading. Studies are now underway to more fully elucidate the role of the AF in normal reading. In a recent study with healthy children, Yeatman et al. (2011) measured reading and AF properties in healthy children aged 7-11. Measuring a portion of the white matter where the AF could be isolated, Yeatman et al. found that radial diffusivity is higher for children with better phonological awareness. This correlation is present in the left AF but not in adjacent fascicles or the right AF. These measurements support the hypothesis that the left AF carries signals essential for phonological awareness, an important component of skilled reading.

\section{Temporo-Parietal White Matter}

Klingberg et al. (2000) were the first to report a white matter difference between good and poor adult readers. This difference was confirmed in studies with children (Beaulieu et al. 2005, Deutsch et al. 2005, Nagy et al. 2004, Niogi \& McCandliss 2006), but the precise location of the difference with respect to the major fascicles has been difficult to isolate. The largest difference between good and poor readers is in the corona radiata, a fascicle between the $\mathrm{AF}$ and the large band of callosal fibers. It has not been possible, however, to be confident that the difference is caused by tissue properties confined to the fascicle; alternative hypotheses are described in Ben-Shachar et al. (2007c).

Two problems limit the ability to locate diffusion differences between good and poor readers to a specific fascicle. First, the white matter difference is in a region where several fascicles are in close proximity (Figure 5, see color insert). Second, in most studies the differences were measured by comparing groups of good and poor readers rather than individual subjects, and the location is specified in atlas coordinates. Even when restricted to control groups, any coordinate will have mixtures of fiber groups at a particular coordinate. Hua et al. (2008) document the limits in analyzing specific fascicles in group studies where all the subjects are transformed into a common atlas system. These authors coregistered 28 brains and created a fiber tract template. No voxel in the AF template contained AF data from more than 20 of the 28 subjects; the majority of voxels in the AF template included AF data from less than half of the subjects (10-14). When comparing between two distinct groups (e.g., good and poor readers), the problem may be even worse. Thus, it is difficult to confidently identify a fascicle on the basis of group-averaged differences.

\section{Callosal Pathways}

A postmortem analysis of Dejerine's alexic patient revealed a large set of lesions including damage to the posterior corpus callosum (Dejerine 1891). Dejerine was uncertain of the significance of the callosal lesion, but subsequent neurological studies provided compelling reasons to believe that this pathway carries information that is used in reading (Damasio \& Damasio 1983, Wandell 2011).

Three modern reports in healthy subjects show a correlation between the tissue properties of a posterior callosal region and reading. Specifically, in a small region of the posterior 
callosum, radial diffusivity is correlated with certain behaviors (e.g., phonological awareness) that are essential for skilled reading (Dougherty et al. 2007, Frye et al. 2008, Odegard et al. 2009). Where these fibers project to cortex is unsettled; preliminary analyses in our laboratory suggest that they project to the angular or superior temporal gyrus (Kevan et al. 2012).

\section{DYSLEXIA}

In the Introduction we identified a long-term goal of identifying the computations of all the neural circuits used in reading. It is important to look for ways to use our current understanding even as we work toward the larger goal. One application is to use neuroimaging measurements to predict the likelihood of success of specific interventions. For example, EEG potentials (Maurer et al. 2009, Molfese 2000) and MR measures (Davis et al. 2010; Hoeft et al. 2007, 2011) have been used to predict reading outcomes. Such measures can be used to select the best intervention for an individual (Gabrieli 2009).

Many neuroimaging measurements compare responses in good and poor readers, but there are critical limitations in our ability to explain these findings (Shaywitz et al. 2008). One limitation is the diversity of findings themselves. For example, some investigators report that the principal difference is in temporoparietal cortex, and others report that principal differences are in inferior temporo-occipital cortex. A second limitation concerns how to integrate measurements from different modalities [EEG, MEG, fMRI, and diffusion tensor imaging (DTI)]. The fMRI responses are not driven by the same neural signals that give rise to scalp measurements (Logothetis \& Wandell 2004), and EEG and MEG signals arise from different sources (Sharon et al. 2007). Hence, the N170 measured by an occipital electrode in EEG may not measure the same neural signal as the VWFA response measured by fMRI. To combine the data across the variety of imaging technologies requires models that can integrate the data from different measurements into a coherent understanding of the underlying neural circuitry; such modeling is a hope, not yet a reality.

\section{Good and Poor Readers}

Despite some limitations, neuroimaging has provided useful guidance concerning dyslexia and potential interventions. Using both temporally and spatially resolved methods, many investigators have shown that responses to single-word identification are smaller in left VOT cortex of poor readers compared to good readers.

Salemelin and colleagues reported that MEG responses to words localized to left inferior occipitotemporal cortex differ significantly between good and poor adult readers (Helenius et al. 1999, Salmelin et al. 1996). These responses arise within $200 \mathrm{~ms}$ of stimulus presentation, and the amplitude of these responses is significantly lower in poor readers than in good readers. Using MEG in children, Simos et al. $(2000,2002,2007)$ report differences between poor and good readers in the same left occipitotemporal regions, but at slightly delayed times $(220 \mathrm{~ms})$. They further report differences in left temporo-parietal cortex near the superior temporal gyrus.

The earliest PET and fMRI studies included measurements of responses of good and poor readers. The visualization tools and instrumental sensitivity did not produce a clear picture of the differences. For example, Paulesu et al. (1996) reported differences between controls and compensated adult dyslexics in Broca's area and Wernicke's area, but not in VOT cortex. They concluded that dyslexic subjects "activated the same brain areas as controls, but unlike controls, they did not activate them in concert." Rumsey and colleagues (Rumsey et al. 1997, Horwitz et al. 1998) used a range of behavioral tests to understand the relationship between specific brain regions and different components of reading and found 
many differences between good and poor readers, including a significant VOT response difference on orthographic decision-making (e.g., which is a word: hoal or hole?). Subsequently, Brunswick et al. (1999; Figure 2) and Paulesu et al. (2001; Figure 3) found that good and poor reader responses differed in a region they labeled the left inferior/middle temporal region that falls in VOT cortex at the VWFA location (Wandell 2011; Figure 4).

Pugh et al. (2001) offered a neurobiological account based on a dorsal and ventral stream for reading. They suggested that the dorsal stream, which includes the left angular gyrus, dominates early reading and interpretation of the relationship between orthography and phonology. Over time, the ventral stream, which includes the VOT circuitry, develops into a fast word-recognition system that is needed for fluent reading. Their neurobiological account matches the dual-route theory (Coltheart et al. 2001).

Maisog et al. (2008) performed a quantitative meta-analysis of the literature and found that the most reliable difference between good and poor readers was in left extrastriate cortex, including the region of the VWFA. The reduced responses are not restricted to reading: The region responds less during picture naming, which suggests VOT is involved in integrating phonology and visual information broadly (McCrory et al. 2005).

Although there is general agreement on the importance of VOT cortex, the precision of the measurements could be improved. To visualize the locations identified in several of these reports, we draw the positions as 1-cm-radius disks on segmented cortical gray matter of an individual subject. The gray matter surface is inflated to visualize the sulci (Figure 6, see color insert). In the sidebar titled Responses in the Medial Temporal Gyrus and the VWFA, we describe the challenges in localizing responses in group studies. Additional factors that may contribute to differences between studies are the age of subjects and the fMRI task.

\section{Interventions}

Many recent reading interventions were guided by the hypothesis that dyslexia arises from an inability to perceive and manipulate the sounds of speech (phonological awareness and decoding) (Comm. Prev. Reading Difficulties in Young Children et al. 1998). This hypothesis is based on two key findings. First, a powerful correlation exists between the ability to perceive the sounds of speech and the ability to read (Bradley \& Bryant 1978, Stanovich et al. 1984). Second, explicit training in speech sounds can improve reading (Bradley \& Bryant 1983, Torgesen et al. 1999, Wagner \& Torgesen 1987). Reading interventions based on the phonological awareness theory use a variety of training paradigms. In some interventions children are trained to hear phonemes, in others they are trained to hear the association between sounds and text, and in some cases children are trained to hear nonlanguage sounds such as tones. Modern treatments based on phonological awareness have not ended dyslexia, and there are open questions about the interpretation of phonemic awareness interventions. For example, some authors challenge the hypothesis that learning to hear phonemes, without teaching the sound-text connection, improves reading (Castles \& Coltheart 2004).

Several groups have studied changes in the functional response of poor readers following phonological interventions. For example, in an fMRI study with children, Shaywitz et al. (2004) found that a phonologically based intervention transformed the left occipitotemporal system. In a recent review, they write, "the failure of the word form area to function properly in dyslexic children and young adults is responsible for their characteristic inefficient, slow reading" (Shaywitz \& Shaywitz 2008). Similar increases in left VOT responses after reading interventions have been reported using MEG (Simos et al. 2007). In contrast, Meyler and colleagues (Meyler et al. 2007, 2008) used fMRI to measure the effect of phonological training using a sentence comprehension task. They found that training 
increases responses in the left angular gyrus region. They write, "Conspicuously absent in the present data is any hint of an effect of either reading ability or intensive remediation on activation in left occipito-temporal areas" (Meyler et al. 2008, p. 2588). Eden et al. (2004) measured fMRI responses during phonological tasks in adults who underwent reading remediation. They found an increased response in the left angular gyrus as well as in the fusiform/parahippocampal gyrus anterior to the VWFA. The pattern of outcomes does not simplify by incorporating results from the other investigations (Aylward et al. 2003, Odegard et al. 2008, Temple et al. 2003).

In addition to measurements of functional responses, there are reports that reading interventions change both white matter (Keller \& Just 2009) and gray matter (Krafnick et al. 2011). So far, these measures have failed to find changes in the same reading networks found by fMRI. Many factors could account for these differences, and as measurement technologies improve, we may hope to find converging results across different methodologies.

One hypothesis concerning the effects of remediation is based on the lateralization of reading signals (Pugh et al. 2001). A number of groups have observed that in poor readers responses to words are relatively right lateralized, and that after reading interventions, MEG and fMRI responses in ventral occipital cortex become left lateralized (Maisog et al. 2008, Shaywitz et al. 2008, Simos et al. 2002, Spironelli et al. 2010).

\section{CONCLUSION}

A picture of the functional responses and anatomical structures essential for skilled reading is coming into focus. In the early years of neuroimaging, it might have been hoped that the list would be small and that differences between good and poor readers could be summarized by a spot in cortex or a single lesion in white matter. Just as genomics has taught us that human performance is rarely dependent on a single gene, neuroimaging has taught us that human performance is rarely dependent on a single brain structure or a single class of neurons.

By emphasizing measurements that can be made in individual subjects, we hope to develop methods so that dysfunction can be understood from the differences in an individual who is struggling to read compared to the typical set of responses in good readers. We should anticipate that each individual may deviate in his or her own way, and there may be individualized interventions to address the dysfunction of particular cortical circuits.

As instrumentation and methods improve, we will be able to follow signals and measure structures with increasing precision. Consequently, we will find many more statistically reliable differences between groups or between individuals. Anticipating these advances, we can expect that experimental designs will change from an effort to identify reliable statistical differences to designs that evaluate quantitative models of signals and structures. Individuals may be reliably different from one another, but only some differences will interfere with performance. Hence, we anticipate a future in which the current emphasis on hypothesis testing for differences is replaced by measurements that characterize system performance.

An enormous amount has been learned about the reading circuitry over the past 25 years. In the 1980s, the neural basis of reading was informed mainly by lesion-induced alexias, but reading difficulties in otherwise healthy children were opaque (Wandell 2011). Since those days, we have developed tools that can explore the signals and structures with much better resolution. We have learned how to trace the reading signal as it passes from early visual cortex to VOT, and a compelling case has been made that the VOT contains responses that are essential for reading; these responses can be measured using both spatially and 
temporally resolved signals. The development of these responses has been measured in healthy children and in children and adults undergoing reading interventions. The white matter pathways that carry signals between VOT and anterior cortical regions, such as the angular gyrus and temporo-parietal cortex, may well clarify in the next few years. There is reason to hope that basic investigations into reading circuits will pay off in the form of practical advice about the intervention that is best suited for an individual child.

\section{LITERATURE CITED}

Allison T, McCarthy G, Nobre A, Puce A, Belger A. Human extrastriate visual cortex and the perception of faces, words, numbers, and colors. Cereb. Cortex. 1994; 4:544-54. [PubMed: 7833655]

Amano K, Wandell BA, Dumoulin SO. Visual field maps, population receptive field sizes, and visual field coverage in the human MT+ complex. J. Neurophysiol. 2009; 102:2704-18. [PubMed: 19587323]

Andrews TJ, Halpern SD, Purves D. Correlated size variations in human visual cortex, lateral geniculate nucleus, and optic tract. J. Neurosci. 1997; 17:2859-68. [PubMed: 9092607]

Appelbaum LG, Wade AR, Vildavski VY, Pettet MW, Norcia AM. Cue-invariant networks for figure and background processing in human visual cortex. J. Neurosci. 2006; 26:11695-708. [PubMed: 17093091]

Aylward EH, Richards TL, Berninger VW, Nagy WE, Field KM, et al. Instructional treatment associated with changes in brain activation in children with dyslexia. Neurology. 2003; 61:212-19. [PubMed: 12874401]

Basser P. Inferring microstructural features and the physiological state of tissues from diffusionweighted images. NMR Biomed. 1995; 8:333-44. [PubMed: 8739270]

Beaulieu C, Plewes C, Paulson LA, Roy D, Snook L, et al. Imaging brain connectivity in children with diverse reading ability. NeuroImage. 2005; 25:1266-71. [PubMed: 15850744]

Ben-Shachar M, Dougherty RF, Deutsch GK, Wandell BA. Contrast responsivity in MT+ correlates with phonological awareness and reading measures in children. NeuroImage. 2007a; 37:1396-406. [PubMed: 17689981]

Ben-Shachar M, Dougherty RF, Deutsch GK, Wandell BA. Differential sensitivity to words and shapes in ventral occipito-temporal cortex. Cereb. Cortex. 2007b; 17:1604-11. [PubMed: 16956978]

Ben-Shachar M, Dougherty RF, Deutsch GK, Wandell BA. The development of cortical sensitivity to visual word forms. J. Cogn. Neurosci. 2011 In press.

Ben-Shachar M, Dougherty RF, Wandell BA. White matter pathways in reading. Curr. Opin. Neurobiol. 2007c; 17:258-70. [PubMed: 17379499]

Bentin S, Mouchetant-Rostaing Y, Giard MH, Echallier JF, Pernier J. ERP manifestations of processing printed words at different psycholinguistic levels: time course and scalp distribution. J. Cogn. Neurosci. 1999; 11:235-60. [PubMed: 10402254]

Bernal B, Ardila A. The role of the arcuate fasciculus in conduction aphasia. Brain. 2009; 132:230916. [PubMed: 19690094]

Binder JR, Lazar RM, Tatemichi TK, Mohr JP, Desmond DW, Ciecierski KA. Left hemiparalexia. Neurology. 1992; 42:562-69. [PubMed: 1307679]

Binder JR, Medler DA, Westbury CF, Liebenthal E, Buchanan L. Tuning of the human left fusiform gyrus to sublexical orthographic structure. NeuroImage. 2006; 33:739-48. [PubMed: 16956773]

Booth JR, Burman DD, Van Santen FW, Harasaki Y, Gitelman DR, et al. The development of specialized brain systems in reading and oral-language. Child Neuropsychol. 2001; 7:119-41. [PubMed: 12187470]

Bourgeois J, Rakic P. Changes of synaptic density in the primary visual cortex of the macaque monkey from fetal to adult stage. J. Neurosci. 1993; 13:2801-20. [PubMed: 8331373]

Bradley L, Bryant PE. Difficulties in auditory organisation as a possible cause of reading backwardness. Nature. 1978; 271:746-47. [PubMed: 625341] 
Bradley L, Bryant PE. Categorizing sounds and learning to read—a causal connection. Nature. 1983; 301:419-21.

Braitenberg, V.; Schüz, A. Anatomy of the Cortex: Statistics and Geometry. Springer-Verlag; Berlin: 1991.

Brefczynski JA, DeYoe EA. A physiological correlate of the "spotlight" of visual attention. Nat. Neurosci. 1999; 2:370-74. [PubMed: 10204545]

Brem S, Bach S, Kucian K, Guttorm TK, Martin E, et al. Brain sensitivity to print emerges when children learn letter-speech sound correspondences. Proc. Natl. Acad. Sci. USA. 2010; 107:793944. [PubMed: 20395549]

Brem S, Bucher K, Halder P, Summers P, Dietrich T, et al. Evidence for developmental changes in the visual word processing network beyond adolescence. NeuroImage. 2006; 29:822-37. [PubMed: 16257546]

Brewer AA, Liu J, Wade AR, Wandell BA. Visual field maps and stimulus selectivity in human ventral occipital cortex. Nat. Neurosci. 2005; 8:1102-9. [PubMed: 16025108]

Brunswick N, McCrory E, Price CJ, Frith CD, Frith U. Explicit and implicit processing of words and pseudowords by adult developmental dyslexics: a search for Wernicke's Wortschatz? Brain. 1999; 122(Pt. 10):1901-17. [PubMed: 10506092]

Bub DN, Arguin M, Lecours AR. Jules Dejerine and his interpretation of pure alexia. Brain Lang. 1993; 45:531-59. [PubMed: 8118672]

Cai Q, Lavidor M, Brysbaert M, Paulignan Y, Nazir TA. Cerebral lateralization of frontal lobe language processes and lateralization of the posterior visual word processing system. J. Cogn. Neurosci. 2008; 20:672-81. [PubMed: 18052778]

Cantlon JF, Pinel P, Dehaene S, Pelphrey KA. Cortical representations of symbols, objects, and faces are pruned back during early childhood. Cereb. Cortex. 2011; 21:191-99. [PubMed: 20457691]

Castles A, Coltheart M. Is there a causal link from phonological awareness to success in learning to read? Cognition. 2004; 91:77-111. [PubMed: 14711492]

Catani M, Ffytche DH. The rises and falls of disconnection syndromes. Brain. 2005; 128:2224-39. [PubMed: 16141282]

Catani M, Jones DK, Donato R, Ffytche DH. Occipito-temporal connections in the human brain. Brain. 2003; 126:2093-107. [PubMed: 12821517]

Church JA, Coalson RS, Lugar HM, Petersen SE, Schlaggar BL. A developmental fMRI study of reading and repetition reveals changes in phonological and visual mechanisms over age. Cereb. Cortex. 2008; 18:2054-65. [PubMed: 18245043]

Cohen L, Dehaene S, Naccache L, Lehericy S, Dehaene-Lambertz G, et al. The visual word form area: spatial and temporal characterization of an initial stage of reading in normal subjects and posterior split-brain patients. Brain. 2000; 123(Pt. 2):291-307. [PubMed: 10648437]

Cohen L, Lehericy S, Chochon F, Lemer C, Rivaud S, Dehaene S. Language-specific tuning of visual cortex? Functional properties of the visual word form area. Brain. 2002; 125:1054-69. [PubMed: 11960895]

Cohen L, Martinaud O, Lemer C, Lehericy S, Samson Y, et al. Visual word recognition in the left and right hemispheres: anatomical and functional correlates of peripheral alexias. Cereb. Cortex. 2003; 13:1313-33. [PubMed: 14615297]

Coltheart M, Rastle K, Perry C, Langdon R, Ziegler J. DRC: a dual route cascaded model of visual word recognition and reading aloud. Psychol. Rev. 2001; 108:204-56. [PubMed: 11212628]

Coltheart M, Tree JJ, Saunders SJ. Computational modeling of reading in semantic dementia: comment on Woollams, Lambon Ralph, Plaut, and Patterson (2007). Psychol. Rev. 2010; 117:256-71. discussion 271-72. [PubMed: 20063972]

Snow, CE.; Burns, MS.; Griffin, P. Preventing Reading Difficulties in Young Children. Natl. Acad. Press; Washington, DC: 1998. Comm. Prev. Reading Difficulties in Young Children; p. 432

Conturo TE, Lori NF, Cull TS, Akbudak E, Snyder AZ, et al. Tracking neuronal fiber pathways in the living human brain. Proc. Natl. Acad. Sci. USA. 1999; 96:10422-27. [PubMed: 10468624]

Cornelissen PL, Hansen PC, Gilchrist I, Cormack F, Essex J, Frankish C. Coherent motion detection and letter position encoding. Vision Res. 1998; 38:2181-91. [PubMed: 9797977] 
Dale AM, Sereno MI. Improved localization of cortical activity by combining EEG and MEG with MRI cortical surface reconstruction: a linear approach. J. Cogn. Neurosci. 1993; 5:162-76.

Damasio AR, Damasio H. The anatomic basis of pure alexia. Neurology. 1983; 33:1573-83. [PubMed: 6685830]

Danielian LE, Iwata NK, Thomasson DM, Floeter MK. Reliability of fiber tracking measurements in diffusion tensor imaging for longitudinal study. NeuroImage. 2010; 49:1572-80. [PubMed: 19744567]

Davis N, Fan Q, Compton DL, Fuchs D, Fuchs LS, et al. Influences of neural pathway integrity on children's response to reading instruction. Front. Syst. Neurosci. 2010; 4:150. [PubMed: 21088707]

Dehaene S, Jobert A, Naccache L, Ciuciu P, Poline JB, et al. Letter binding and invariant recognition of masked words: behavioral and neuroimaging evidence. Psychol. Sci. 2004; 15:307-13. [PubMed: 15102139]

Dehaene S, Naccache L, Cohen L, Bihan DL, Mangin JF, et al. Cerebral mechanisms of word masking and unconscious repetition priming. Nat. Neurosci. 2001; 4:752-58. [PubMed: 11426233]

Dehaene S, Nakamura K, Jobert A, Kuroki C, Ogawa S, Cohen L. Why do children make mirror errors in reading? Neural correlates of mirror invariance in the visual word form area. NeuroImage. 2010a; 49:1837-48. [PubMed: 19770045]

Dehaene S, Pegado F, Braga LW, Ventura P, Nunes Filho G, et al. How learning to read changes the cortical networks for vision and language. Science. 2010b; 330:1359-64. [PubMed: 21071632]

Dejerine J. Sur un cas de cecite verbale avec agraphie, suivi d'autopsie. Mém. Soc. Biol. 1891; 3:197201.

Dejerine J. Contribution a l'étude anatomoclinique etclinique des differentes varietes de cecite verbal. C. R. Hebd. Séances Mém. Soc. Biol. 1892; 4:61-90.

Dejerine, J. Anatomie des Centres Nerveux. Rueff; Paris: 1895.

Demb JB, Boynton GM, Heeger DH. Brain activity in visual cortex predicts individual differences in reading performance. Proc. Natl. Acad. Sci. USA. 1997; 94:13363-66. [PubMed: 9371851]

Deutsch GK, Dougherty RF, Bammer R, Siok WT, Gabrieli JD, Wandell B. Children's reading performance is correlated with white matter structure measured by diffusion tensor imaging. Cortex. 2005; 41:354-63. [PubMed: 15871600]

Devlin JT, Jamison HL, Gonnerman LM, Matthews PM. The role of the posterior fusiform gyrus in reading. J. Cogn. Neurosci. 2006; 18:911-22. [PubMed: 16839299]

Dougherty RF, Ben-Shachar M, Deutsch GK, Hernandez A, Fox GR, Wandell BA. Temporal-callosal pathway diffusivity predicts phonological skills in children. Proc. Natl. Acad. Sci. USA. 2007; 104:8556-61. [PubMed: 17483487]

Dougherty RF, Koch VM, Brewer AA, Fischer B, Modersitzki J, Wandell BA. Visual field representations and locations of visual areas V1/2/3 in human visual cortex. J. Vis. 2003; 3:58698. [PubMed: 14640882]

Dumoulin SO, Wandell BA. Population receptive field estimates in human visual cortex. NeuroImage. 2008; 39:647-60. [PubMed: 17977024]

Eden GF, Jones KM, Cappell K, Gareau L, Wood FB, et al. Neural changes following remediation in adult developmental dyslexia. Neuron. 2004; 44:411-22. [PubMed: 15504323]

Eden GF, VanMeter JW, Rumsey JM, Maisog JM, Woods RP, Zeffiro TA. Abnormal processing of visual motion in dyslexia revealed by functional brain imaging. Nature. 1996; 382:66-69. [PubMed: 8657305]

Epelbaum S, Pinel P, Gaillard R, Delmaire C, Perrin M, et al. Pure alexia as a disconnection syndrome: new diffusion imaging evidence for an old concept. Cortex. 2008; 44:962-74. [PubMed: 18586235]

Epstein R, Kanwisher N. A cortical representation of the local visual environment. Nature. 1998; 392:598-601. [PubMed: 9560155]

Fischl B, van der Kouwe A, Destrieux C, Halgren E, Segonne F, et al. Automatically parcellating the human cerebral cortex. Cereb. Cortex. 2004; 14:11-22. [PubMed: 14654453] 
Friedmann N, Gvion A. Sentence comprehension and working memory limitation in aphasia: a dissociation between semantic-syntactic and phonological reactivation. Brain Lang. 2003; 86:2339. [PubMed: 12821413]

Frye RE, Hasan K, Xue L, Strickland D, Malmberg B, et al. Splenium microstructure is related to two dimensions of reading skill. Neuroreport. 2008; 19:1627-31. [PubMed: 18806688]

Gabrieli JD. Dyslexia: a new synergy between education and cognitive neuroscience. Science. 2009; 325:280-83. [PubMed: 19608907]

Gaillard R, Naccache L, Pinel P, Clemenceau S, Volle E, et al. Direct intracranial, FMRI, and lesion evidence for the causal role of left inferotemporal cortex in reading. Neuron. 2006; 50:191-204. [PubMed: 16630832]

Gandhi SP, Heeger DJ, Boynton GM. Spatial attention affects brain activity in human primary visual cortex. Proc. Natl. Acad. Sci. USA. 1999; 96:3314-19. [PubMed: 10077681]

Geschwind N. Disconnexion syndromes in animals and man. I. Brain. 1965a; 88:237-94. [PubMed: 5318481]

Geschwind N. Disconnexion syndromes in animals and man. II. Brain. 1965b; 88:585-644. [PubMed: 5318824]

Glasser MF, Rilling JK. DTI tractography of the human brain's language pathways. Cereb. Cortex. 2008; 18:2471-82. [PubMed: 18281301]

Goodman CS, Shatz CJ. Developmental mechanisms that generate precise patterns of neuronal connectivity. Cell. 1993; 72(Suppl.):77-98. [PubMed: 8428376]

Grünling C, Ligges M, Huonker R, Klingert M, Mentzel H-J, et al. Dyslexia: the possible benefit of multimodal integration of fMRI- and EEG-data. J. Neural Transm. 2004; 111:951-69. [PubMed: 15206009]

Hagler DJ Jr, Halgren E, Martinez A, Huang M, Hillyard SA, Dale AM. Source estimates for MEG/ EEG visual evoked responses constrained by multiple, retinotopically-mapped stimulus locations. Hum. Brain Mapp. 2009; 30:1290-309. [PubMed: 18570197]

Helenius P, Tarkiainen A, Cornelissen P, Hansen PC, Salmelin R. Dissociation of normal feature analysis and deficient processing of letter-strings in dyslexic adults. Cereb. Cortex. 1999; 9:47683. [PubMed: 10450892]

Henschen SE. On the visual path and centre. Brain. 1893; 16:170-80.

Hickok G, Poeppel D. Dorsal and ventral streams: a framework for understanding aspects of the functional anatomy of language. Cognition. 2004; 92:67-99. [PubMed: 15037127]

Hickok G, Poeppel D. The cortical organization of speech processing. Nat. Rev. Neurosci. 2007; 8:393-402. [PubMed: 17431404]

Hoeft F, McCandliss BD, Black JM, Gantman A, Zakerani N, et al. Neural systems predicting longterm outcome in dyslexia. Proc. Natl. Acad. Sci. USA. 2011; 108:361-66. [PubMed: 21173250]

Hoeft F, Ueno T, Reiss AL, Meyler A, Whitfield-Gabrieli S, et al. Prediction of children's reading skills using behavioral, functional, and structural neuroimaging measures. Behav. Neurosci. 2007; 121:602-13. [PubMed: 17592952]

Holmes G. Disturbances of vision by cerebral lesions. Br. J. Ophthalmol. 1918; 2:353-84. [PubMed: 18167806]

Holmes AP, Blair RC, Watson JD, Ford I. Nonparametric analysis of statistic images from functional mapping experiments. J. Cereb. Blood Flow Metab. 1996; 16:7-22. [PubMed: 8530558]

Horton JC, Hoyt WF. Quadrantic visual field defects: a hallmark of lesions in extrastriate (V2/V3) cortex. Brain. 1991a; 114:1703-18. [PubMed: 1884174]

Horton JC, Hoyt WF. The representation of the visual field in human striate cortex. A revision of the classic Holmes map. Arch. Ophthalmol. 1991b; 109:816-24. [PubMed: 2043069]

Horwitz B, Rumsey JM, Donohue BC. Functional connectivity of the angular gyrus in normal reading and dyslexia. Proc. Natl. Acad. Sci. USA. 1998; 95:8939-44. [PubMed: 9671783]

Howard D, Patterson K, Wise R, Brown WD, Friston K, et al. The cortical localization of the lexicons. Positron emission tomography evidence. Brain. 1992; 115(Pt. 6):1769-82. [PubMed: 1486460] 
Hua K, Zhang J, Wakana S, Jiang H, Li X, et al. Tract probability maps in stereotaxic spaces: analyses of white matter anatomy and tract-specific quantification. NeuroImage. 2008; 39:336-47. [PubMed: 17931890]

Huk AC, Dougherty RF, Heeger DJ. Retinotopy and functional subdivision of human areas MT and MST. J. Neurosci. 2002; 22:7195-205. [PubMed: 12177214]

Inouye, T. Die Sehstörungen bei Schussverletzungen der kortikalen Sehsphäre. Engelmann; Leipzig, Germany: 1909.

Jobard G, Crivello F, Tzourio-Mazoyer N. Evaluation of the dual route theory of reading: a metaanalysis of 35 neuroimaging studies. NeuroImage. 2003; 20:693-712. [PubMed: 14568445]

Kanwisher N. Faces and places: of central (and peripheral) interest. Nat. Neurosci. 2001; 4:455-56. [PubMed: 11319548]

Kanwisher N, McDermott J, Chun MM. The fusiform face area: a module in human extrastriate cortex specialized for face perception. J. Neurosci. 1997; 17:4302-11. [PubMed: 9151747]

Kay KN, Naselaris T, Prenger RJ, Gallant JL. Identifying natural images from human brain activity. Nature. 2008; 452:352-55. [PubMed: 18322462]

Keller TA, Just MA. Altering cortical connectivity: remediation-induced changes in the white matter of poor readers. Neuron. 2009; 64:624-31. [PubMed: 20005820]

Kevan, A.; Perry, LM.; Rykhlevskaia, E.; Ben-Shachar, M.; Sherbondy, A., et al. White matter pathways between callosum and posterior superior temporal cortex predict phonological skills in children. 2011. Manuscript submitted

Klingberg T, Hedehus M, Temple E, Salz T, Gabrieli JD, et al. Microstructure of temporo-parietal white matter as a basis for reading ability: evidence from diffusion tensor magnetic resonance imaging. Neuron. 2000; 25:493-500. [PubMed: 10719902]

Kolster H, Peeters R, Orban GA. The retinotopic organization of the human middle temporal area MT/ V5 and its cortical neighbors. J. Neurosci. 2010; 30:9801-20. [PubMed: 20660263]

Krafnick AJ, Flowers DL, Napoliello EM, Eden GF. Gray matter volume changes following reading intervention in dyslexic children. NeuroImage. 2011 In press.

Lebel C, Walker L, Leemans A, Phillips L, Beaulieu C. Microstructural maturation of the human brain from childhood to adulthood. NeuroImage. 2008; 40:1044-55. [PubMed: 18295509]

Le Bihan D, Mangin JF, Poupon C, Clark CA, Pappata S, et al. Diffusion tensor imaging: concepts and applications. J. Magn. Reson. Imaging. 2001; 13:534-46. [PubMed: 11276097]

Leff AP, Crewes H, Plant GT, Scott SK, Kennard C, Wise RJ. The functional anatomy of single-word reading in patients with hemianopic and pure alexia. Brain. 2001; 124:510-21. [PubMed: 11222451]

Livingstone MS, Rosen GD, Drislane FW, Galaburda AM. Physiological and anatomical evidence for a magnocellular defect in developmental dyslexia. Proc. Natl. Acad. Sci USA. 1991; 88:7943-47. [PubMed: 1896444]

Logothetis NK, Wandell BA. Interpreting the BOLD signal. Annu. Rev. Physiol. 2004; 66:735-69. [PubMed: 14977420]

Lovegrove W, Martin F, Bowling A, Blackwood M, Badcock D, Paxton S. Contrast sensitivity functions and specific reading disability. Neuropsychologia. 1982; 20:309-15. [PubMed: 7121798]

Lovegrove WJ, Bowling A, Badcock D, Blackwood M. Specific reading-disability: differences in contrast sensitivity as a function of spatial-frequency. Science. 1980; 210:439-40. [PubMed: 7433985]

Maisog JM, Einbinder ER, Flowers DL, Turkeltaub PE, Eden GF. A meta-analysis of functional neuroimaging studies of dyslexia. Ann. N. Y. Acad. Sci. 2008; 1145:237-59. [PubMed: 19076401]

Maunsell JH, Nealey TA, DePriest DD. Magnocellular and parvocellular contributions to responses in the middle temporal visual area (MT) of the macaque monkey. J. Neurosci. 1990; 10:3323-34. [PubMed: 2213142]

Maurer U, Blau VC, Yoncheva YN, McCandliss BD. Development of visual expertise for reading: rapid emergence of visual familiarity for an artificial script. Dev. Neuropsychol. 2010; 35:40422. [PubMed: 20614357] 
Maurer U, Brem S, Bucher K, Kranz F, Benz R, et al. Impaired tuning of a fast occipito-temporal response for print in dyslexic children learning to read. Brain. 2007; 130:3200-10. [PubMed: 17728359]

Maurer U, Bucher K, Brem S, Benz R, Kranz F, et al. Neurophysiology in preschool improves behavioral prediction of reading ability throughout primary school. Biol. Psychiatry. 2009; 66:341-48. [PubMed: 19423082]

McCandliss BD, Cohen L, Dehaene S. The visual word form area: expertise for reading in the fusiform gyrus. Trends Cogn. Sci. 2003; 7:293-99. [PubMed: 12860187]

McCrory EJ, Mechelli A, Frith U, Price CJ. More than words: a common neural basis for reading and naming deficits in developmental dyslexia? Brain. 2005; 128:261-67. [PubMed: 15574467]

Meyler A, Keller TA, Cherkassky VL, Gabrieli JD, Just MA. Modifying the brain activation of poor readers during sentence comprehension with extended remedial instruction: a longitudinal study of neuroplasticity. Neuropsychologia. 2008; 46:2580-92. [PubMed: 18495180]

Meyler A, Keller TA, Cherkassky VL, Lee D, Hoeft F, et al. Brain activation during sentence comprehension among good and poor readers. Cereb. Cortex. 2007; 17:2780-87. [PubMed: 17317678]

Molfese DL. Predicting dyslexia at 8 years of age using neonatal brain responses. Brain Lang. 2000; 72:238-45. [PubMed: 10764519]

Mori, S. Introduction to Diffusion Tensor Imaging. Elsevier; Amsterdam: 2007.

Mori S, Crain BJ, Chacko VP, van Zijl PC. Three-dimensional tracking of axonal projections in the brain by magnetic resonance imaging. Ann. Neurol. 1999; 45:265-69. [PubMed: 9989633]

Murphy KM, Beston BR, Boley PM, Jones DG. Development of human visual cortex: a balance between excitatory and inhibitory plasticity mechanisms. Dev. Psychobiol. 2005; 46:209-21. [PubMed: 15772972]

Nagy Z, Westerberg H, Klingberg T. Maturation of white matter is associated with the development of cognitive functions during childhood. J. Cogn. Neurosci. 2004; 16:1227-33. [PubMed: 15453975]

Niogi SN, McCandliss BD. Left lateralized white matter microstructure accounts for individual differences in reading ability and disability. Neuropsychologia. 2006; 44:2178-88. [PubMed: 16524602]

Nobre AC, Allison T, McCarthy G. Word recognition in the human inferior temporal lobe. Nature. 1994; 372:260-63. [PubMed: 7969469]

O'Craven KM, Rosen BR, Kwong KK, Treisman A, Savoy RL. Voluntary attention modulates fMRI activity in human MT-MST. Neuron. 1997; 18:591-98. [PubMed: 9136768]

Odegard TN, Farris EA, Ring J, McColl R, Black J. Brain connectivity in non-reading impaired children and children diagnosed with developmental dyslexia. Neuropsychologia. 2009; 47:1972-77. [PubMed: 19428430]

Odegard TN, Ring J, Smith S, Biggan J, Black J. Differentiating the neural response to intervention in children with developmental dyslexia. Ann. Dyslexia. 2008; 58:1-14. [PubMed: 18483867]

Paulesu E, Connelly A, Frith CD, Friston KJ, Heather J, et al. Functional MR imaging correlations with positron emission tomography. Initial experience using a cognitive activation paradigm on verbal working memory. Neuroimaging Clin. N. Am. 1995; 5:207-25. [PubMed: 7640885]

Paulesu E, Demonet JF, Fazio F, McCrory E, Chanoine V, et al. Dyslexia: cultural diversity and biological unity. Science. 2001; 291:2165-67. [PubMed: 11251124]

Paulesu E, Frith U, Snowling M, Gallagher A, Morton J, et al. Is developmental dyslexia a disconnection syndrome? Evidence from PET scanning. Brain. 1996; 119:143-57. [PubMed: 8624677]

Pegado F, Nakamura K, Cohen L, Dehaene S. Breaking the symmetry: mirror discrimination for single letters but not for pictures in the visual word form area. NeuroImage. 2010; 55:742-49. [PubMed: 21111052]

Petersen S, Fox P, Posner M, Mintun M, Rachle M. Positron emission tomographic studies of the cortical anatomy of single-word processing. Nature. 1988; 331:585-89. [PubMed: 3277066]

Petersen SE, Fiez JA. The processing of single words studied with positron emission tomography. Annu. Rev. Neurosci. 1993; 16:509-30. [PubMed: 8460901] 
Powell HW, Parker GJ, Alexander DC, Symms MR, Boulby PA, et al. Hemispheric asymmetries in language-related pathways: a combined functional MRI and tractography study. NeuroImage. 2006; 32:388-99. [PubMed: 16632380]

Price CJ, Devlin JT. The myth of the visual word form area. NeuroImage. 2003; 19:473-81. [PubMed: 12880781]

Price CJ, Devlin JT. The pro and cons of labelling a left occipitotemporal region: "the visual word form area.". NeuroImage. 2004; 22:477-79. [PubMed: 15110041]

Price CJ, Howard D, Patterson K, Warburton EA, Friston KJ, Frackowiak SJ. A functional neuroimaging description of two deep dyslexic patients. J. Cogn. Neurosci. 1998; 10:303-15. [PubMed: 9869706]

Price CJ, Wise RJ, Watson JD, Patterson K, Howard D, Frackowiak RS. Brain activity during reading. The effects of exposure duration and task. Brain. 1994; 117(Pt. 6):1255-69. [PubMed: 7820564]

Pugh KR, Mencl WE, Jenner AR, Katz L, Frost SJ, et al. Neurobiological studies of reading and reading disability. J. Commun. Disord. 2001; 34:479-92. [PubMed: 11725860]

Rauschecker AM, Deutsch GK, Ben-Shachar M, Schwartzman A, Perry LM, Dougherty RF. Reading impairment in a patient with missing arcuate fasciculus. Neuropsychologia. 2009; 47:180-94. [PubMed: 18775735]

Rilling JK, Glasser MF, Preuss TM, Ma X, Zhao T, et al. The evolution of the arcuate fasciculus revealed with comparative DTI. Nat. Neurosci. 2008; 11:426-28. [PubMed: 18344993]

Rossion B, Gauthier I, Goffaux V, Tarr MJ, Crommelinck M. Expertise training with novel objects leads to left-lateralized facelike electrophysiological responses. Psychol. Sci. 2002; 13:250-57. [PubMed: 12009046]

Rumsey JM, Nace K, Donohue B, Wise D, Maisog JM, Andreason P. A positron emission tomographic study of impaired word recognition and phonological processing in dyslexic men. Arch. Neurol. 1997; 54:562-73. [PubMed: 9152113]

Salmelin R, Helenius P, Service E. Neurophysiology of fluent and impaired reading: a magnetoencephalographic approach. J. Clin. Neurophysiol. 2000; 17:163-74. [PubMed: 10831107]

Salmelin R, Service E, Kiesila P, Uutela K, Salonen O. Impaired visual word processing in dyslexia revealed with magnetoencephalography. Ann. Neurol. 1996; 40:157-62. [PubMed: 8773596]

Saur D, Kreher BW, Schnell S, Kummerer D, Kellmeyer P, et al. Ventral and dorsal pathways for language. Proc. Natl. Acad. Sci. USA. 2008; 105:18035-40. [PubMed: 19004769]

Sharon D, Hamalainen MS, Tootell RB, Halgren E, Belliveau JW. The advantage of combining MEG and EEG: comparison to fMRI in focally stimulated visual cortex. NeuroImage. 2007; 36:122535. [PubMed: 17532230]

Shaywitz BA, Shaywitz SE, Blachman BA, Pugh KR, Fulbright RK, et al. Development of left occipitotemporal systems for skilled reading in children after a phonologically based intervention. Biol. Psychiatry. 2004; 55:926-33. [PubMed: 15110736]

Shaywitz SE, Morris R, Shaywitz BA. The education of dyslexic children from childhood to young adulthood. Annu. Rev. Psychol. 2008; 59:451-75. [PubMed: 18154503]

Shaywitz SE, Shaywitz BA. Paying attention to reading: the neurobiology of reading and dyslexia. Dev. Psychopathol. 2008; 20:1329-49. [PubMed: 18838044]

Simos PG, Breier JI, Fletcher JM, Foorman BR, Bergman E, et al. Brain activation profiles in dyslexic children during non-word reading: a magnetic source imaging study. Neurosci. Lett. 2000; 290:61-65. [PubMed: 10925175]

Simos PG, Fletcher JM, Bergman E, Breier JI, Foorman BR, et al. Dyslexia-specific brain activation profile becomes normal following successful remedial training. Neurology. 2002; 58:1203-13. [PubMed: 11971088]

Simos PG, Fletcher JM, Sarkari S, Billingsley RL, Denton C, Papanicolaou AC. Altering the brain circuits for reading through intervention: a magnetic source imaging study. Neuropsychology. 2007; 21:485-96. [PubMed: 17605581]

Song Y, Bu Y, Hu S, Luo Y, Liu J. Short-term language experience shapes the plasticity of the visual word form area. Brain Res. 2010; 1316:83-91. [PubMed: 20034482] 
Sowell ER, Thompson PM, Toga AW. Mapping changes in the human cortex throughout the span of life. Neuroscientist. 2004; 10:372-92. [PubMed: 15271264]

Sperling AJ, Lu ZL, Manis FR, Seidenberg MS. Deficits in perceptual noise exclusion in developmental dyslexia. Nat. Neurosci. 2005; 8:862-63. [PubMed: 15924138]

Sperling AJ, Lu ZL, Manis FR, Seidenberg MS. Motion-perception deficits and reading impairment: it's the noise, not the motion. Psychol. Sci. 2006; 17:1047-53. [PubMed: 17201786]

Spironelli C, Angrilli A. Developmental aspects of automatic word processing: language lateralization of early ERP components in children, young adults and middle-aged subjects. Biol. Psychol. 2009; 80:35-45. [PubMed: 18343558]

Spironelli C, Penolazzi B, Vio C, Angrilli A. Cortical reorganization in dyslexic children after phonological training: evidence from early evoked potentials. Brain. 2010; 133:3385-95. [PubMed: 20688811]

Stanovich KE, Cunningham AE, Cramer BB. Assessing phonological awareness in kindergarten children: issues of task comparability. J. Exp. Child Psychol. 1984; 38:175-90.

Stein J. The magnocellular theory of developmental dyslexia. Dyslexia. 2001; 7:12-36. [PubMed: 11305228]

Stensaas SS, Eddington DK, Dobelle WH. The topography and variability of the primary visual cortex in man. J. Neurosurg. 1974; 40:747-55. [PubMed: 4826600]

Szwed M, Cohen L, Qiao E, Dehaene S. The role of invariant line junctions in object and visual word recognition. Vision Res. 2009; 49:718-25. [PubMed: 19200808]

Szwed M, Dehaene S, Kleinschmidt A, Eger E, Valabregue R, et al. Specialization for written words over objects in the visual cortex. NeuroImage. 2011; 56:330-44. [PubMed: 21296170]

Tarr MJ, Gauthier I. FFA: a flexible fusiform area for subordinate-level visual processing automatized by expertise. Nat. Neurosci. 2000; 3:764-69. [PubMed: 10903568]

Temple E, Deutsch GK, Poldrack RA, Miller SL, Tallal P, et al. Neural deficits in children with dyslexia ameliorated by behavioral remediation: evidence from functional MRI. Proc. Natl. Acad. Sci. USA. 2003; 100:2860-65. [PubMed: 12604786]

Thirion B, Duchesnay E, Hubbard E, Dubois J, Poline JB, et al. Inverse retinotopy: inferring the visual content of images from brain activation patterns. NeuroImage. 2006; 33:1104-16. [PubMed: 17029988]

Tolstoy, L. Anna Karenina. John Lane; New York: 1911. p. 919

Tootell RB, Dale AM, Sereno MI, Malach R. New images from human visual cortex. Trends Neurosci. 1996; 19:481-89. [PubMed: 8931274]

Tootell RB, Reppas JB, Kwong KK, Malach R, Born RT, et al. Functional analysis of human MT and related visual cortical areas using magnetic resonance imaging. J. Neurosci. 1995; 15:3215-30. [PubMed: 7722658]

Tootell RB, Taylor JB. Anatomical evidence for MT and additional cortical visual areas in humans. Cereb. Cortex. 1995; 5:39-55. [PubMed: 7719129]

Torgesen JK, Wagner RK, Rashotte CA, Rose E, Lindamood P, et al. Preventing reading failure in children with phonological processing difficulties: group and individual responses to instruction. J. Educ. Psychol. 1999; 81:579-93.

Turkeltaub PE, Flowers DL, Lyon LG, Eden GF. Development of ventral stream representations for single letters. Ann. N. Y. Acad. Sci. 2008; 1145:13-29. [PubMed: 19076386]

Twomey T, Kawabata Duncan KJ, Price CJ, Devlin JT. Top-down modulation of ventral occipitotemporal responses during visual word recognition. NeuroImage. 2011; 55:1242-51. [PubMed: 21232615]

Van Essen DC, Lewis JW, Drury HA, Hadjikhani N, Tootell RB, et al. Mapping visual cortex in monkeys and humans using surface-based atlases. Vision Res. 2001; 41:1359-78. [PubMed: 11322980]

Vigneau M, Beaucousin V, Herve PY, Jobard G, Petit L, et al. What is right-hemisphere contribution to phonological, lexico-semantic, and sentence processing? Insights from a meta-analysis. NeuroImage. 2011; 54:577-93. [PubMed: 20656040] 
Vinckier F, Dehaene S, Jobert A, Dubus JP, Sigman M, Cohen L. Hierarchical coding of letter strings in the ventral stream: dissecting the inner organization of the visual word-form system. Neuron. 2007; 55:143-56. [PubMed: 17610823]

Wagner RK, Torgesen JK. The nature of phonological processing and its causal role in the acquisition of reading skills. Psychol. Bull. 1987; 101:192-212.

Wakana S, Jiang H, Nagae-Poetscher LM, van Zijl PC, Mori S. Fiber tract-based atlas of human white matter anatomy. Radiology. 2004; 230:77-87. [PubMed: 14645885]

Walhovd KB, Fjell AM, Reinvang I, Lundervold A, Dale AM, et al. Effects of age on volumes of cortex, white matter and subcortical structures. Neurobiol. Aging. 2005; 26:1261-70. discussion 75-78. [PubMed: 16005549]

Wandell BA. The neurobiological basis of seeing words. Ann. N. Y. Acad. Sci. 2011; 1224:63-80. [PubMed: 21486296]

Wandell BA, Dumoulin SO, Brewer AA. Visual field maps in human cortex. Neuron. 2007; 56:36683. [PubMed: 17964252]

Wandell BA, Smirnakis SM. Plasticity and stability of visual field maps in adult primary visual cortex. Nat. Rev. Neurosci. 2009; 10:873-84. [PubMed: 19904279]

Wandell BA, Winawer J. Imaging retinotopic maps in the human brain. Vision Res. 2010; 51:718-37. [PubMed: 20692278]

Warrington EK, Shallice T. Word-form dyslexia. Brain. 1980; 103:99-112. [PubMed: 6244876]

Wernicke, C.; Eggert, GH. Wernicke's Works on Aphasia: A Sourcebook and Review. Mouton; The Hague: 1874. Der aphasischer Symptomenkomplex: eine psychologische Studie auf anatomischer Basis.; p. 91-145.

Wernicke, C. Wernicke's Works on Aphasia: A Sourcebook and Review. Mouton; The Hague: 1906. Der aphasischer Symptomenkomplex. Die deutsche Klinik am Eingdnge des 20 Jahrhunderts.; p. 487

Winawer J, Horiguchi H, Sayres RA, Amano K, Wandell BA. Mapping hV4 and ventral occipital cortex: the venous eclipse. J. Vis. 2010; 10:1. [PubMed: 20616143]

Xue G, Chen C, Jin Z, Dong Q. Language experience shapes fusiform activation when processing a logographic artificial language: an fMRI training study. NeuroImage. 2006; 31:1315-26. [PubMed: 16644241]

Yeatman JD, Dougherty R, Rykhlevskaia E, Sherbondy A, Deutsch G, et al. Anatomical properties of the arcuate fasciculus predict phonological and reading skills in children. J. Cogn. Neurosci. 2011 In press.

Yoncheva YN, Zevin JD, Maurer U, McCandliss BD. Auditory selective attention to speech modulates activity in the visual word form area. Cereb. Cortex. 2010; 20:622-32. [PubMed: 19571269]

Yushkevich PA, Piven J, Hazlett HC, Smith RG, Ho S, et al. User-guided 3D active contour segmentation of anatomical structures: significantly improved efficiency and reliability. NeuroImage. 2006; 31:1116-28. [PubMed: 16545965]

Zeki S. The response properties of cells in the middle temporal area (area MT) of owl monkey visual cortex. Proc. R. Soc. Lond. B Biol. Sci. 1980; 207:239-48. [PubMed: 6102766]

Zeki S. The Ferrier Lecture 1995 behind the seen: the functional specialization of the brain in space and time. Philos. Trans. R. Soc. Lond. B Biol. Sci. 2005; 360:1145-83. [PubMed: 16147515]

Zeki S, Watson JD, Lueck CJ, Friston KJ, Kennard C, Frackowiak RS. A direct demonstration of functional specialization in human visual cortex. J. Neurosci. 1991; 11:641-49. [PubMed: 2002358] 
Orthography: the written or printed symbols of language

Developmental dyslexia: failure or difficulty learning to read in a child whose cognitive skills are otherwise unimpaired

MEG: magnetoencephalography

EEG: electroencephalography

V1: primary visual cortex 
Pure alexia: the inability to read even when visual and language functions are intact; also known as word blindness and alexia without agraphia

VOT: ventral occipitotemporal cortex

VWFA: visual word form area 
fMRI: functional magnetic resonance imaging

Retinotopic maps: mapping of visual space onto the brain surface such that neighboring neurons respond to neighboring parts of the visual field 
Magnetic susceptibility: the degree of magnetization of the material or tissue in response to a magnetic field applied by the MR scanner 
hMT+: human motion complex

Phonological awareness: ability to manipulate the sounds of speech ("What is bat minus / b/ ?'); used as a predictor of reading difficulties

VWFA response sensitivity: a stimulus-referred approach where the responses to a stimulus embedded in multiple levels of noise are measured 
Phonology: the study of how sounds are organized and used in natural languages 
AF: arcuate fasciculus

Radial diffusivity: the apparent diffusivity measured in the direction perpendicular to the length of a fascicle; to be differentiated from the apparent diffusivity measured along the length (axial diffusivity) 


\section{DTI: diffusion tensor imaging}




\section{RESPONSES IN THE MEDIAL TEMPORAL GYRUS AND THE VWFA}

Acquiring MRI data involves many experimental and processing choices, each of which may have important consequences for scientific conclusions. The MRI acquisition and processing choices can be opaque to casual readers of the MRI literature. This side-bar illustrates the impact that certain methodological choices can have on scientific conclusions.

When measuring the whole brain, investigators use a range of voxel sizes and smoothing. It is not uncommon to see measurements with $5-\mathrm{mm}$ isotropic voxels followed by $9-\mathrm{mm}$ FWHM (full width at half maximum) spatial averaging. In this case, functional signals from a single point in the brain are pooled over a region roughly the size of the overlaid disks (Figure 7, see color insert). Data in many studies are further combined across brains, each with its own unique gyral and sulcal patterns.

An anatomical region in the VOT is shown in a single coronal slice in Figure 7. The point labeled on the lateral aspect of the brain is near the middle temporal gyrus; the point labeled on the ventral surface is in the occipitotemporal sulcus. These regions are separated by centimeters when measured along the cortical surface. However, they are separated by only $\sim 4-5 \mathrm{~mm}$ in the brain volume. If one pools fMRI signals over 5- to 10$\mathrm{mm}$ regions, there is no realistic chance of reliably distinguishing responses originating near the middle temporal gyrus from those in the occipitotemporal sulcus. This confusion is very problematic because a long history of neuroscientific exploration has established that the organization and computation of neurons is best understood by proximity on the cortical sheet. Neurons that are nearby in the volume only due to the cortical folding pattern may perform very different functions, and their responses should not be averaged.

This problem is not unique to the study of reading or VOT. As a second example, consider the pre- and postcentral gyri, which perform motor and somatosensory functions, respectively. These gyri are in close proximity within the volume, but one would not want to average their responses. Throughout the brain, regions at the bottom of sulci are in close proximity when described in the volume; these regions are separated by less than $1 \mathrm{~cm}$ when measured through the white matter. One indication of imprecise spatial positioning is the localization of principal activation to the white matter rather than the gray matter.

Modern MRI scanners can perform functional measurements at 2-mm or better resolution within individual subjects. Because the cortical sheet thickness is 2 to $3 \mathrm{~mm}$, and the opposite sides of sulci are separated by about $2 \mathrm{~mm}$, smaller voxels reduce the scope of the problem. Better spatial localization of the signals can be achieved by segmenting white and gray matter and averaging along the gray matter surface. Tools for achieving good segmentations are now freely distributed and are commonly used in certain subfields of neuroimaging (Fischl et al. 2004, Yushkevich et al. 2006).

Issues of spatial resolution are also important to consider in diffusion imaging and tractography (Figure 7, right side). Notice that the white matter separating various sulci on the lateral and ventral surface is about 3- to 5-mm thick. The standard size of a diffusion voxel is $2 \mathrm{~mm}$ isotropic, so that for tractography one would obtain no more than two measurements between the opposite sides of a typical gyrus. Given these measurement limitations, we do not obtain precise information about the location on a gyrus where a fascicular projection terminates. A fair heuristic of the measurement precision is to imagine a surface connecting the base of the sulci (Figure 7, red outline). Projections of the white matter up to this surface, before the white matter becomes thin in the gyri, are relatively secure. The figure illustrates that we can obtain better estimates of fascicles projecting to some cortical regions than others. Given diffusion measurements 
with sufficiently high signal to noise, the shape and gross trajectory of major white matter fascicles and their diffusion characteristics can be reliably measured in individuals (Danielian et al. 2010). 


\section{FUTURE ISSUES}

1. Understand the spatio-temporal reading circuitry transformations from input (retina/V1), through visual, auditory, and language circuitry, to output (semantic access).

2. Quantify the developmental trajectory of gray and white matter structures used for reading.

3. Identify specific structural or functional deficiencies in individual subjects with reading difficulties.

4. Associate specific behavioral traits with specific neural differences.

5. Predict reading difficulties and the likely success of individualized interventions from neuroimaging or behavioral measurements. 


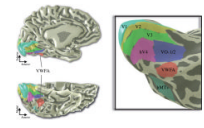

Figure 1.

The location of the VWFA in relation to visual field maps. The left images are medial (top) and ventral (bottom) views of the left hemisphere of a single subject. The surface was defined by segmenting the gray and white matter. The gray shading codes surface curvature: sulci (dark) and gyri (light). The colored overlays denote the locations of visual field maps and the VWFA that were measured in this subject using fMRI. The image on the right is an expanded view of the VOT cortex, computationally inflated in order to visualize the depths of the sulci. The individual maps are labeled. The VWFA position is shown as a $10-\mathrm{mm}$ radius disk, centered at standard MNI coordinates for the VWFA [ $-44-58-15]$ (Jobard et al. 2003). fMRI, functional magnetic resonance imaging; MNI, Montreal Neurological Institute; VOT, ventral occipitotemporal; VWFA, visual word form area. 


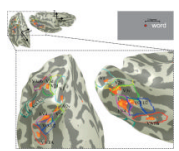

Figure 2.

Measuring responses to words within the human visual field maps. A word presented just to the right of fixation (inset, upper right) produces predictably localized responses in the hierarchy of the outlined visual field maps (matching Figure 1). Two views of the left hemisphere of a subject (inset, upper left) are shown expanded in the two main images. The orange overlays represent the amplitudes of functional magnetic resonance imaging responses in a single subject. The posterior view (left) is positioned to show visualization of the dorsal (V2d, V3d, V3a/b, LO-1, LO-2, TO-1, and TO-2) and ventral (V2v, V3v, hV4, VO-1, and VO-2) visual field maps and the visual word form area. The ventral view (right) emphasizes visualization of activity along the ventral visual field maps. The dotted arrows on the ventral view indicate the proposed information flow between the maps, possibly via U-fibers. 


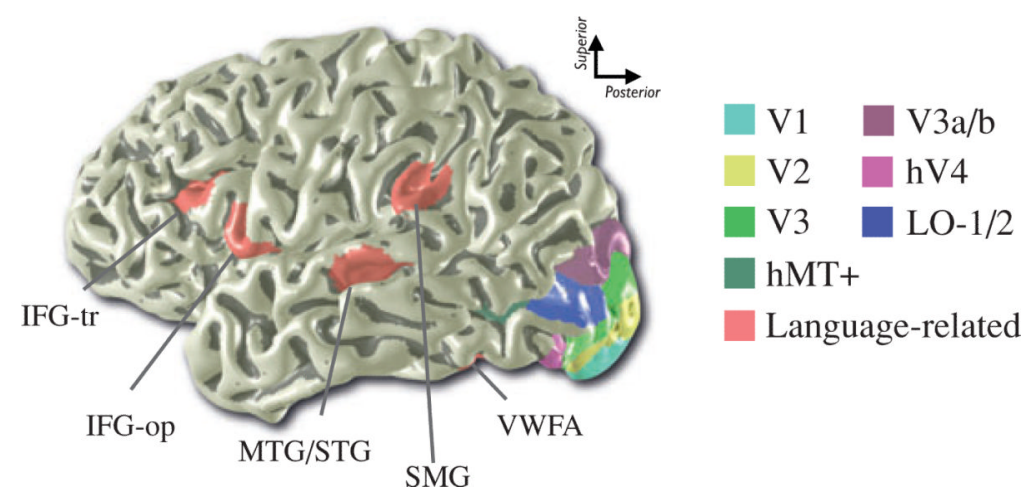

Figure 3.

Left hemisphere reading-related areas. The red color overlays on this lateral view of a left hemisphere are relatively anterior cortical locations that are active during reading tasks. The color overlays in the posterior region are the locations of visual field maps in this individual subject. Language-related regions are placed at the MNI coordinates in Jobard et al. (2003). IFG-tr, inferior frontal gyrus, pars triangularis; IFG-op, inferior frontal gyrus, pars opercularis; MTG/STG, middle/superior temporal gyrus, including superior temporal sulcus; SMG, supramarginal gyrus; VWFA, visual word form area. 


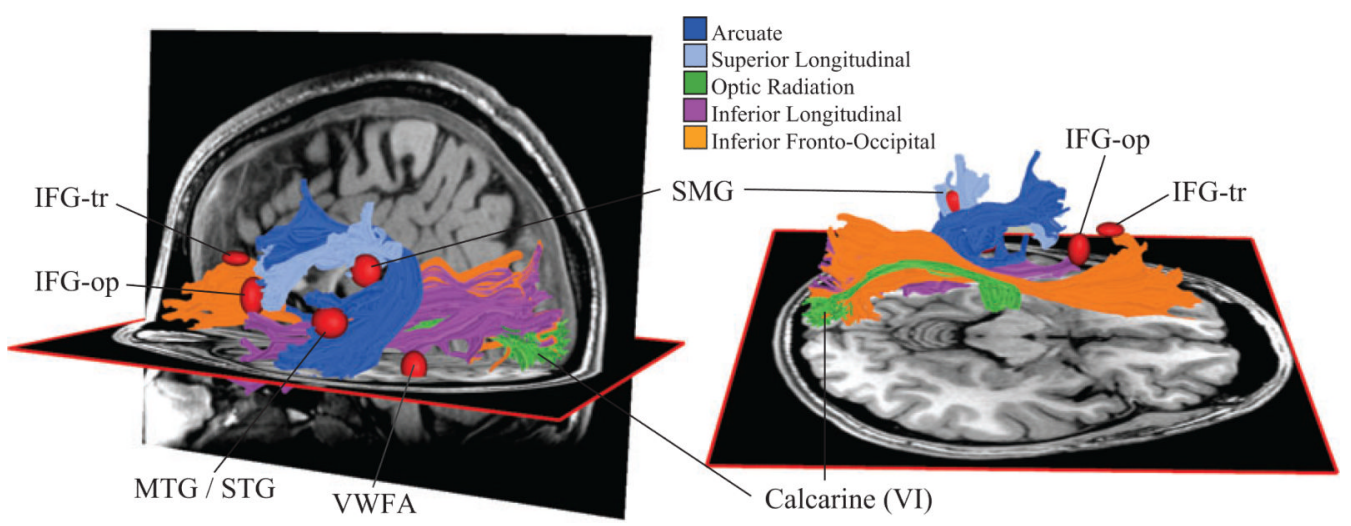

Figure 4.

White matter pathways that carry essential reading signals. The two images show several major white matter fascicles in the left hemisphere from different points of view. Three of these fascicles communicate information to and from the occipital lobe. The red ellipsoids are located near cortical regions that respond (fMRI) during reading tasks (Jobard et al. 2003); these are the same locations as shown in Figure 3. The ellipsoids are scaled to reflect the uncertainty (standard deviation) of the center positions, measured across studies. The arcuate and superior longitudinal fasciculi include axons that terminate near these cortical regions. 


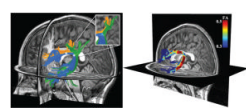

Figure 5.

The arcuate fasciculus contains axons that communicate between phonological processing regions. The image on the left shows the arcuate fasciculus (blue) and two adjacent fascicles (orange and green) that pass through the same voxels that contain arcuate axons. The inset shows an expanded view of the region containing these three pathways and their divergent directions. In the image on the right, the arcuate is colored to indicate the fractional anisotropy (FA) along its trajectory. Some of the FA variation is due to tract curvature and partial voluming with neighboring anatomical structures. For example, FA is low at the arcing location where several distinct groups of fibers converge (left image). The effect of such geometric properties and partial voluming can be reduced by measuring the FA in the anterior portion of the tract, which is relatively straight, and the arcuate can be distinguished from nearby tracts. 


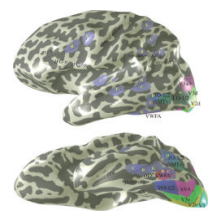

Figure 6.

Cortical regions where fMRI responses differ between good and poor readers. Lateral (top) and ventral (bottom) view of a computationally inflated left hemisphere. The visual field maps were measured using fMRI. Other labeled regions ( purple with yellow letters) were identified as showing greater responses to visual word stimuli in controls than dyslexics. The positions are reported by $(A)$ Paulesu et al. (1996), (B) Rumsey et al. (1997), (C) Brunswick et al. (1999), (D) Paulesu et al. (2001), (E) Eden et al. (2004), $(F)$ Grünling et al. (2004), $(G)$ McCrory et al. (2005). Several of these regions are in VOT, either overlapping or near the VWFA location, which is centered at standard MNI coordinates [ $-44-58-15]$ (Jobard et al. 2003). 


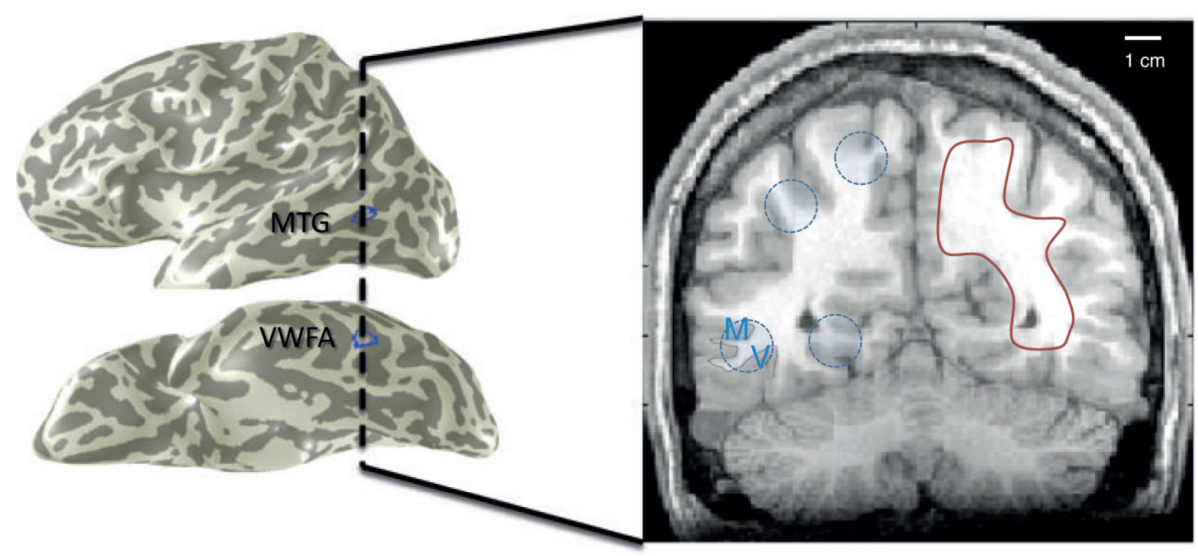

Figure 7.

Spatial resolution considerations when analyzing functional responses and white matter pathways using magnetic resonance imaging. 